\title{
Enhancement of Soluble Expression and Biochemical Characterization of Two Epoxide Hydrolases from Bacillus
}

\author{
Li-Ying Wu ${ }^{1}$, Jun-Jie $\mathrm{Xu}^{1}$, Pan $\mathrm{Xu}{ }^{2}$, Bin Yong ${ }^{2, *}$, Hong Feng ${ }^{1, *}$ \\ ${ }^{1}$ Key Laboratory of Bio-Resource and Eco-Environment of Ministry of Education, College of Life Sciences, Sichuan \\ University; Sichuan Key Laboratory of Molecular Biology and Biotechnology, Chengdu 610065, Sichuan, P. R. China \\ ${ }^{2}$ College of Life Sciences, Sichuan Normal University, Chengdu 610101, Sichuan, P. R. China \\ * Corresponding author:
}

Hong Feng, Key Laboratory of Bio-Resource and Eco-Environment of Ministry of Education, College of Life Sciences, Sichuan University; Sichuan Key Laboratory of Molecular Biology and Biotechnology, Chengdu 610065, Sichuan, P. R. China; Tel: +86-28-8547 0226; Fax: +86-28-8541 2738; Email: hfeng@scu.edu.cn

Bin Yong, College of Life Sciences, Sichuan Normal University, Chengdu 610101, Sichuan, P. R. China; Tel: +86-28-8448 0653; Fax: +86-28-8448 0655; E-mail: binyong1225@163.com

\begin{abstract}
Background: Enantiopure epoxides are important intermediates in the synthesis of high-value chiral chemicals. Epoxide hydrolases have been exploited in biocatalysis for kinetic resolution of racemic epoxides to produce enantiopure epoxides and vicinal diols. It is necessary to obtain sufficient stable epoxide hydrolases with high enantioselectivity to meet the requirements of industry.

Objectives: Enhancement of soluble expression and biochemical characterization of epoxide hydrolases from Bacillus pumilus and B. subtilis.

Material and Methods: Homologous genes encoding epoxide hydrolases from B. pumilus and B. subtilis were cloned and expressed in Escherichia coli. The recombinant epoxide hydrolases were characterized biochemically.

Results: Low temperature induction of expression and a C-terminal-fused His-tag enhanced soluble expression of the epoxide hydrolases from the two Bacillus species in E. coli. These epoxide hydrolases could hydrolyze various epoxide substrates, with stereoselectivity toward some epoxides such as styrene oxide and glycidyl tosylate.

Conclusions: The position of the His-tag and the induction temperature were found to play a vital role in soluble expression of these two epoxide hydrolases in E. coli. In view of their catalytic properties, the epoxide hydrolases from Bacillus have potential for application in kinetic resolution of some epoxides to prepare enantiopure epoxides and vicinal diols.
\end{abstract}

Keywords: Bacillus; Epoxide Hydrolase; Hydrolysis

\section{Background}

Enantiopure epoxides are attractive intermediates for use in synthesis of high-value-added chiral chemicals, like pharmaceuticals. Therefore, chemical and biocatalytic procedures have been developed to prepare enantiopure epoxides from racemic mixtures by kinetic resolution (1-3). With the development of green chemistry, biocatalysis is recognized as one of the most promising strategies for hydrolytic kinetic resolution of racemic epoxides $(4,5)$.

Epoxide hydrolases (EHs; EC 3.3.2.3), present in bacteria, fungi, insects, plants and human $(6,7)$, can catalyze the hydrolysis of epoxides into corresponding vicinal diols via a trans opening of the oxirane with a varied range of stereoselectivities $(8,9)$. Therefore, racemic epoxides can be kinetically resolved by EHs in biocatalytic reactions to produce enantiopure epoxides and vicinal diols. Several microbial EHs have been exploited on the laboratory scale for this purpose (1014), but commercial availability of EHs is limited, although EHs from Aspergillus niger and Rhodococcus rhodochrous are available from Sigma-Aldrich as lyophilized powder (5). Great efforts are still being made to exploit novel EHs from various sources (14-16) and to improve the properties of EHs by protein engineering (17-19). Many recombinant EHs have been expressed in Escherichia coli (20-22); unfortunately, 
these usually form inclusion bodies (23). Optimization of expression conditions, especially to enhance the enzyme solubility, is a prerequisite to obtain enough active and stable $\mathrm{EH}$ for biocatalytic industrial applications.

\section{Objective}

The primary objectives of this study were to recombinantly express and characterize homologous EHs from Bacillus pumilus and B. subtilis. Soluble expression of these two EHs in E. coli was improved by using a lower induction temperature and a C-terminalfused His-tag. Biochemical characterization indicated that these Bacillus EHs have potential for application in chiral resolution of certain epoxides.

\section{Materials and Methods}

\subsection{Materials}

Racemic styrene oxide (SO) and its $(R)-/(S)$ enantiomers, $(R)-/(S)$-epichlorohydrin $(\mathrm{ECH})$, and $(R)$-/(S)-1,2-epoxybutane (EPB) were purchased from Sigma-Aldrich Co. (St Louis, MO, USA). Racemic ECH and $\mathrm{EPB}$, as well as $(R)-/(S)$-glycidyl tosylate (GT), were obtained from Kemiou Chemical Reagent Co. (Tianjin, China). Pfu DNA polymerase was purchased from Tiangen Biotech Co. (Beijing, China). Restriction enzymes and T4 DNA ligase were from Thermo Electron Co. (Waltham, MA, USA). An E.Z.N.A. ${ }^{\circledR}$ Cycle Pure Kit was from Omega Bio-Tek Co. (Norcross, GA,
USA). HisTrap FF Crude $1 \mathrm{~mL}$ columns were purchased from GE Healthcare (Boston, MA, USA).

\subsection{Cloning and Construction of Expression Vectors}

In the genomes of B. subtilis S1-4 (GenBank accession no. NZ_ANIP00000000) (24) and B. pumilus BA06 (GenBank accession no. NZ_AMDH00000000) (25), homologous genes were found to encode EHs. These two EHs were assigned as BsuEH (GenBank accession no. WP_014479220) and BpuEH (GenBank accession no. WP_008342154).

Based on the coding sequences of BpuEH and BsuEH, primers were designed to amplify these genes (Table 1 ). The PCR reaction was set up in $50 \mu \mathrm{L}$ mixtures containing 10 ng genomic DNA, $200 \mathrm{nM}$ dNTP, $40 \mathrm{nM}$ each primer (B06-2817F/R; S-3919F/R), and 2.5 U Pfu DNA polymerase.

The reaction conditions were: $94^{\circ} \mathrm{C}$ for $4 \mathrm{~min} ; 30$ cycles of $94^{\circ} \mathrm{C}$ for $30 \mathrm{~s}, 54^{\circ} \mathrm{C}$ for $30 \mathrm{~s}$, and $72^{\circ} \mathrm{C}$ for $1 \mathrm{~min}$; and a final extension at $72^{\circ} \mathrm{C}$ for $10 \mathrm{~min}$. The PCR products were purified using the E.Z.N.A. ${ }^{\oplus}$ Cycle Pure Kit and digested with restriction enzymes Hind III and $\mathrm{BamH} \mathrm{I}$. The DNA fragments were ligated with vector pET28 digested with the same restriction enzymes, resulting in the expression vectors pET28BpuEH.N $\mathrm{N}_{(\mathrm{His})}$ and pET28BsuEH.N $($ His $)$ with a His-tag at the N-terminus of the recombinant protein. The recombinant vectors were confirmed by DNA sequencing using BigDye Terminator v3.1 (Life Technologies Co., Carlsbad, CA, USA).

Table 1. Primers used in cloning epoxide hydrolase genes from B. pumilus and B. subtilis

\begin{tabular}{|c|c|c|}
\hline Primers & Sequence $\left(5^{\prime}-3^{\prime}\right)$ & Remarks \\
\hline B06-2817F & GGAATTCATATGGATCAAGTTGAGTTTCAAT & Hind III \\
\hline B06-2817R & ATAGGATCCTTATGTTAAAAATTCGAGTATGAG & BamH I \\
\hline S-3919F & GGAATTCATATGGACGGAGTTAAATGCCAG & Hind III \\
\hline S-3919R & ATAGGATCCTTATTGGTTCTTAAGATATTCC & BamH I \\
\hline S3919M.F & CTGCT $\boldsymbol{C} \boldsymbol{C A C G \boldsymbol { G } A T T T C C T A G T T T T G G T A C ~}$ & Deletion of $\mathrm{Nco}$ I \\
\hline S3919M.R & AAAT $\boldsymbol{C} \boldsymbol{C} \boldsymbol{G} \boldsymbol{T} \boldsymbol{G} \boldsymbol{G A G C A G G A C A A T T A A C G G}$ & Deletion of Nco I \\
\hline B2817Nc.F & GGCTTT $\boldsymbol{C} \boldsymbol{C A T G G A T C A A G T T G A G T T T C A A T ~}$ & Nco I \\
\hline B2817Xh.R & CGCTT TCTCGAGTGTAAAAATTCGAGTATGAGCTT & Xho I \\
\hline S3919Nc.F & GGCTTT $\boldsymbol{C} \boldsymbol{C A T \boldsymbol { G } G A C G G A G T T A A A T G C C A G T T ~}$ & Nco I \\
\hline S3919Xh.R & CGCTTT CTCGAGTTGGTTCTTAAGATATTCCAA & Xho I \\
\hline
\end{tabular}

For construction of expression vectors pET28BpuEH.C $\mathrm{C}_{(\mathrm{His})}$ and $\mathrm{pET} 28 \mathrm{BpuEH} . \mathrm{C}_{(\mathrm{His})}$ with the His-tag at the C-terminus, similar experimental procedures were carried out as above, but primers B2817Nc.F/B2817Xh.R and S3919Nc.F/S3919Xh.R were used respectively. Before constructing pET28BsuEH.C (His), $_{\text {, }}$ PCR-based site-directed mutagenesis was performed using primers S3919M.F/R to make a substitution of $\mathrm{T}$ with $\mathrm{C}$, which led to deletion of the Nco I site present in the coding sequence of $B s u E H$. This substitution did not change the encoded amino acid residue.

3.3. Recombinant Protein Expression and Purification Each expression vector was transformed into competent cells of $E$. coli BL21 (DE3), which were purchased from Tiangen Biotech Co. An overnight culture $(5 \mathrm{~mL})$ was inoculated into $1 \mathrm{~L}$ Luria-Bertani broth containing 50 $\mu$ g. $\mathrm{mL}^{-1}$ kanamycin, which was incubated at $37^{\circ} \mathrm{C}$ with shaking at $200 \mathrm{rpm}$ in a ZWT-211B Incubator Shaker (Shanghai Zhicheng Co. Shanghai, China). After the cells reached an optical density at $600 \mathrm{~nm}\left(\mathrm{OD}_{600}\right)$ of $0.6-0.8,0.5 \mathrm{~mL}$ of $1 \mathrm{M}$ isopropyl- $\beta$-D-thiogalactoside was added to the culture (final concentration $0.5 \mathrm{mM}$ ). The culture was then incubated at $18^{\circ} \mathrm{C}$ for an additional $24 \mathrm{~h}$. The cells were harvested by centrifugation using a Centrifuge 5804R (Eppendorf Co., Hamburg, Germany) at $4,600 \times g$ for $10 \mathrm{~min}$ at $4{ }^{\circ} \mathrm{C}$. The cell pellet was resuspended in $25 \mathrm{~mL}$ disruption buffer $(20 \mathrm{mM}$ $\mathrm{K}_{2} \mathrm{HPO}_{4} / \mathrm{KH}_{2} \mathrm{PO}_{4}, \mathrm{pH} 7.5,250 \mathrm{mM} \mathrm{NaCl}, 0.5 \mathrm{mM}$ phenylmethylsulfonyl fluoride, and $10 \%$ glycerol), and sonicated using an Ultrasonic Homogenizer Sonicator (Cole-Parmer Co., Vernon Hills, USA) in an ice bath. 
The lysate was clarified at $15,500 \times g$ for $10 \mathrm{~min}$ at $4{ }^{\circ} \mathrm{C}$. The supernatant was loaded onto a HisTrap FF Crude 1 $\mathrm{mL}$ column with immobilized nickel ions using an ÄKTA Prime System (Amersham, San Francisco, USA). The recombinant proteins were eluted with $0-1 \mathrm{M}$ imidazole.

The fractions with an absorption peak at $280 \mathrm{~nm}$ were pooled and dialyzed against 100 volumes of dialysis buffer $\left[10 \mathrm{mM} \mathrm{K} \mathrm{HPO}_{4} / \mathrm{KH}_{2} \mathrm{PO}_{4}, \mathrm{pH} 7.5,250 \mathrm{mM}\right.$ $\mathrm{NaCl}, 10 \%$ glycerol, $0.1 \mathrm{mM}$ ethylenediaminetetraacetic acid (EDTA)] at $4{ }^{\circ} \mathrm{C}$ overnight. The protein sample was concentrated to about $1 \mathrm{~mL}$ by addition of polyethylene glycol (molecular weight, 20,000). Protein purity was determined by $12 \%$ SDS-PAGE and protein concentration was quantified using AlphaImager software (Alpha Innotech Co., San Leandro, USA) with bovine serum albumin (BSA) as a standard.

\subsection{Epoxide Hydrolase Activity Assay}

The EH activity was assayed with 4-nitrobenzylpyridine reagent as described previously (26). Briefly, the standard reaction was set up in $100 \mu \mathrm{L}$ mixture $(0.1 \mathrm{M}$ phosphate buffer, $\mathrm{pH} 7.5$ ) containing $30 \mathrm{mM}$ substrate and $5 \mu \mathrm{g}$ recombinant $\mathrm{EH}$ protein. The catalytic reaction was performed at $35^{\circ} \mathrm{C}$ for $10 \mathrm{~min}$ or the indicated time. Reagent A ( $100 \mu \mathrm{L} ; 50 \mathrm{mM}$ 4-nitrobenzylpyridine in $80 \%$ ethylene glycol, $20 \%$ acetone $[\mathrm{v} / \mathrm{v}]$ ) was then added. The mixture was heated at $80^{\circ} \mathrm{C}$ for $10 \mathrm{~min}$. After cooling to room temperature, $180 \mu \mathrm{L}$ of the mixture was diluted into 2,520 $\mu \mathrm{L}$ of $0.1 \mathrm{M}$ phosphate buffer $(\mathrm{pH}$ 7.5 ), and then $900 \mu \mathrm{L}$ of reagent B (50\% triethylamine and $50 \%$ acetone $[\mathrm{v} / \mathrm{v}]$ ) were added. Finally, the residual substrate was measured by reading $\mathrm{OD}_{565}$ on a UV-2450 spectrophotometer (Shimadzu, Tokyo, Japan).

The enzymatic activity was calculated according to a standard curve made using the same procedures as above with a range of concentrations of each substrate. For determination of catalytic progress over time, a master mixture $(600 \mu \mathrm{L})$ was set up which contained 30 $\mu \mathrm{g}$ enzyme and $30 \mathrm{mM}$ substrate. The reaction conditions were as above. At indicated time points, 100 $\mu \mathrm{L}$ reaction sample was withdrawn and the residual substrate was determined as described above.

\subsection{Optimal $p H$ and Temperature for Hydrolytic Reaction}

Racemic GT was selected as the substrate to determine the optimal $\mathrm{pH}$ and temperature for enzyme activity. The activity assay was performed as described above but using $2.5 \mu \mathrm{g}$ purified enzyme and $30 \mathrm{mM}$ substrate. The $\mathrm{pH}$ values were 6.0 to 9.0 in $0.1 \mathrm{M}$ phosphate buffer $(\mathrm{pH}$ $6.0-7.8$ ) or $0.1 \mathrm{M}$ Tris- $\mathrm{HCl}$ buffer ( $\mathrm{pH} 7.8-9.0)$. To examine the effect of temperature on the catalytic activity, the reaction was incubated for $30 \mathrm{~min}$ at 20, 25, $30,35,40,45$, and $50^{\circ} \mathrm{C}$.
3.6. Effects of Various Chemicals on Hydrolytic Reaction

The effects of various chemicals on enzyme activity were determined using racemic $\mathrm{SO}$ as substrate. The reaction was set up in $100 \mu \mathrm{L} 0.1 \mathrm{M}$ phosphate buffer ( $\mathrm{pH} 7.5)$ containing $2.5 \mu \mathrm{g}$ purified enzyme and $30 \mathrm{mM}$ substrate. The tested chemicals were: metal ions $\left(\mathrm{Mg}^{2+}, \mathrm{Ca}^{2+}\right.$, $\mathrm{Mn}^{2+}, \mathrm{Cu}^{2+}, \mathrm{Zn}^{2+}$ and $\mathrm{Ba}^{2+}$ ) at $2.0 \mathrm{mM}$; organic cosolvents (acetonitrile and ethanol, 10\% v/v); $5 \mathrm{mM}$ EDTA-Na $\mathrm{N}_{2}$; and $2 \%$ SDS. The enzyme activity was calculated relative to that in the absence of added chemicals, which was defined as $100 \%$.

\subsection{Determination of Enantioselectivity}

Enantioselective hydrolysis of several enantiopure epoxides by the recombinant EHs was investigated. Briefly, $(R)$-and $(S)$-enantiomers of SO, ECH, EPB and GT were chosen as the substrates to examine the enantioselective hydrolysis using $5 \mu \mathrm{g}$ enzyme and 30 $\mathrm{mM}$ substrate in $100 \mu \mathrm{L} 0.1 \mathrm{M}$ phosphate buffer $(\mathrm{pH}$ 7.5). The hydrolytic reaction was performed at $35^{\circ} \mathrm{C}$ for $30 \mathrm{~min}$.

All the above activity assays were performed with three repeats. The data are presented as the average value with the experimental deviation.

\subsection{Sequence Analysis of Epoxide Hydrolases}

Sequence similarity searches were performed using BLASTp (https://www.ncbi.nlm.nih.org). A multiple sequence alignment of $\mathrm{EHs}$ from various organisms was constructed using the software Clustal $\mathrm{X}$ v1.83 (www.clustal.org) and BioEdit v7.2.5 (https://bioedit.updatestar.com/).

\section{Results}

4.1. Sequence Analysis of the Epoxide Hydrolases from two Bacillus Species

The EHs from various Bacillus strains were previously exploited in kinetic resolution of racemic epoxides (2729).

When examining the genomes of B. subtilis S1-4 (24) and B. pumilus BA06 (25), homologous genes were found to encode EHs and their coding sequences were different from the $\mathrm{EH}$-encoding genes of other Bacillus species such as B. megaterium and B. cereus (Fig. 1). However, BpuEH and BsuEH share conserved sequence motifs of EHs, including a catalytic triad (AspAsp-His), an oxyanion hole (HGFP), and two Tyr residues that are involved in substrate binding and assist in the ring-opening of epoxide by acting as proton donor to the epoxide oxygen $(6,7,10)$.

\subsection{Recombinant Expression and Purification of $\mathrm{BsuEH}$ and $\mathrm{BpuEH}$}

Our initial results showed that recombinant BsuEH and $\mathrm{BpuEH}$ with a His-tag at the $\mathrm{N}$-terminus were almost entirely expressed in insoluble form at $37^{\circ} \mathrm{C}$ (Fig. 2A, left panel). 


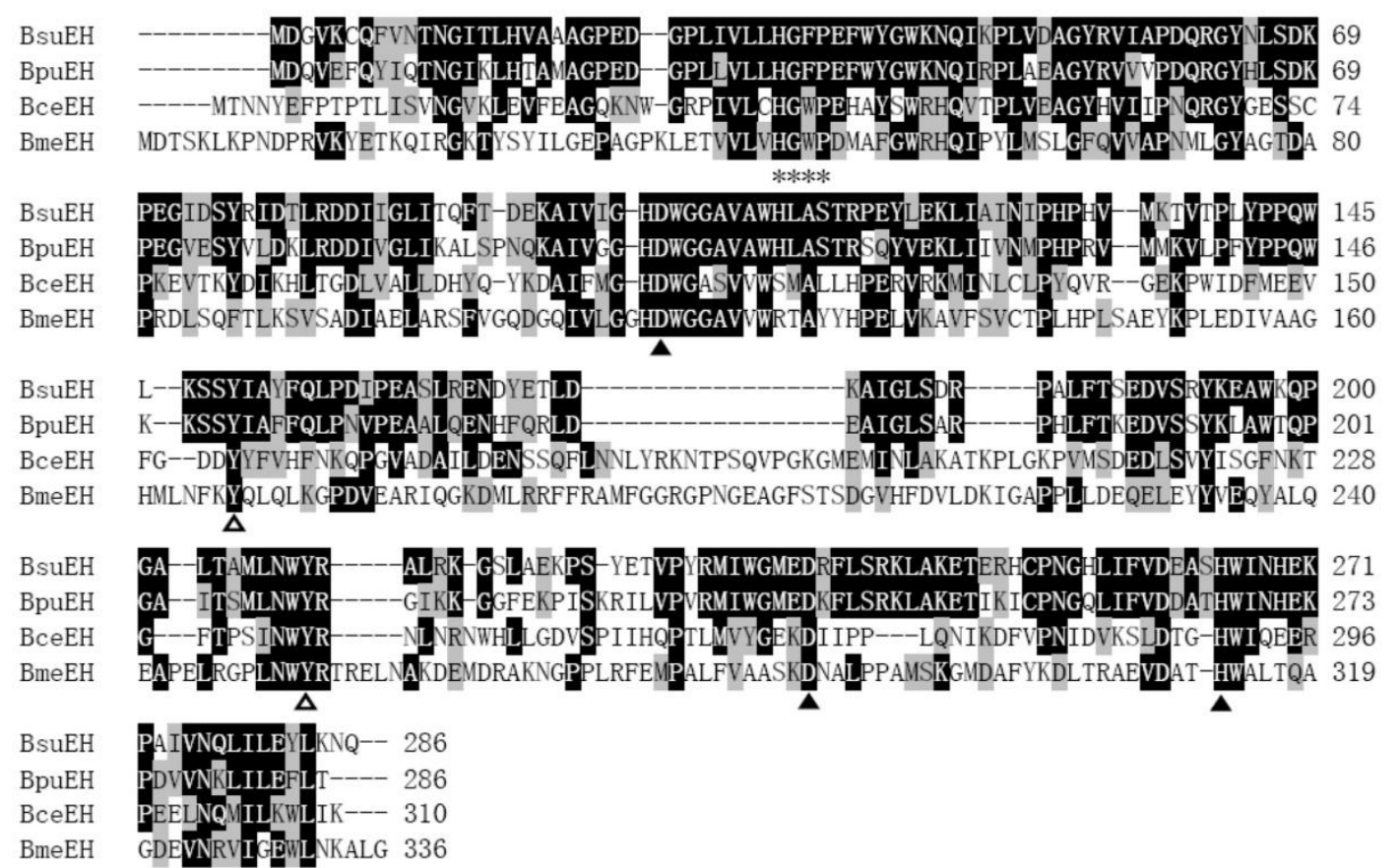

Figure 1. Multiple sequence alignment of epoxide hydrolases (EHs) from Bacillus subtilis (BsuEH, GenBank accession no. WP_014479220), B. pumilus (BpuEH, GenBank accession no. WP_008342154), B. cereus (BceEH, GenBank Accession no. KXY30655), and B. megaterium (BmeEH, GenBank Accession no. ADV36302). Solid triangles indicate putative active site residues (Asp-Asp-His); empty triangles indicate two Tyr residues involved in catalysis; stars indicate the conserved oxyanion hole (HGFP motif).

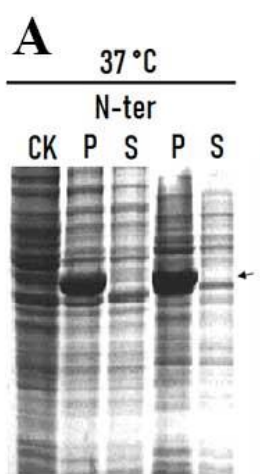

BpuEH BsuEH

C

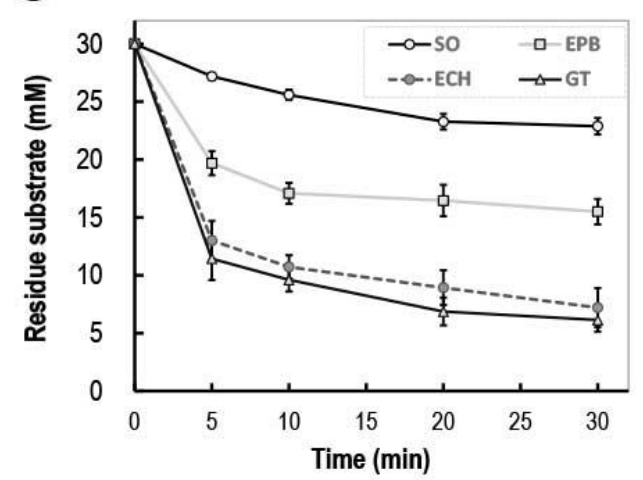

B

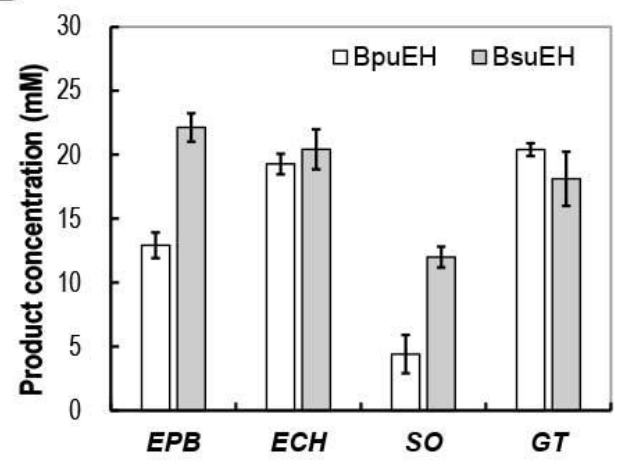

D

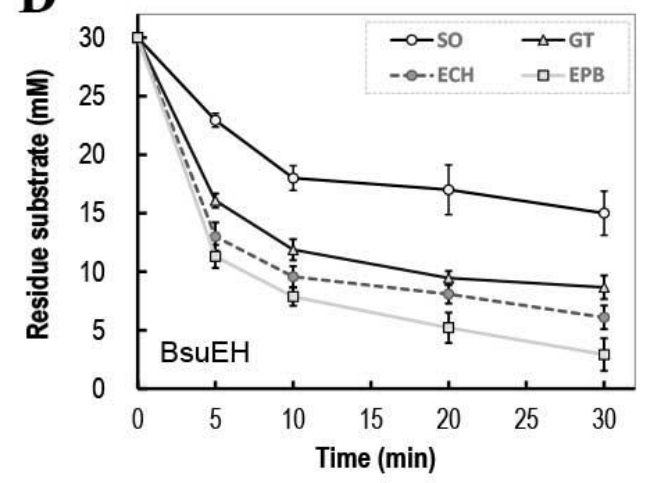

Figure 2. Overexpression of epoxide hydrolases (BpuEH and BsuEH) from B. pumilus and B. subtilis and their hydrolytic reactions toward various epoxide substrates. A: SDS-PAGE analysis of recombinant BpuEH and BsuEH with a His-tag fused to the N-or C-terminus. CK, not induced with isopropyl- $\beta$-D-thiogalactoside; $P$, precipitate fraction of the whole cell lysate; $S$, supernatant fraction of the whole cell lysate; WC, whole cell lysate. The arrows indicate the recombinant proteins. B: Hydrolysis of racemic epoxides by BpuEH and BsuEH. C and D: Hydrolytic progress of BpuEH and BsuEH toward racemic epoxides. The reaction was performed in $0.1 \mathrm{M}$ phosphate buffer ( $\mathrm{pH} 7.5)$ using $5 \mu \mathrm{g}$ enzyme and $30 \mathrm{mM}$ substrate at $35^{\circ} \mathrm{C}$. EPB, $1,2-$ epoxybutane; ECH, epichlorohydrin; SO, styrene oxide; GT, glycidyl tosylate. 
When the induction temperature was changed to $18{ }^{\circ} \mathrm{C}$, soluble EHs could be detected by SDS-PAGE (Fig. 2A, right panel). However, the amount of soluble EHs was still limited.

Since His-tag position significantly influences the soluble expression of some heterologous genes in E. coli (30), expression vectors were constructed with the Histag moved to the C-terminus [pET28BpuEH.C $\mathrm{C}_{(\mathrm{His})}$ and pET28BsuEH.C. (His) $]$ and were used to express the EHs with induction at $18{ }^{\circ} \mathrm{C}$. Figure $2 \mathrm{~A}$ (right panel) shows that the amount of soluble protein was greatly enhanced for both EHs in comparison with that with His-tag at Nterminus, indicating that the position of the His-tag indeed played an important role in soluble expression of these EHs. The recombinant proteins BsuEH and $\mathrm{BpuEH}$ were purified by nickel affinity chromatography and obtained with a C-terminal-fused His-tag. The purified EHs were quantified based the density of protein bands on SDS-PAGE with BSA as a standard.

\subsection{Catalytic Hydrolysis of Various Epoxide} Substrates

Figure 2B shows that both EHs (BpuEH and BsuEH) could hydrolyze the four selected substrates. However, these two EHs exhibited some differences in substrate specificity, which might be due to sequence differences (Fig. 1). The kinetics of the hydrolysis reactions were determined (Fig. 2C, 2D). BpuEH could hydrolyze GT and $\mathrm{ECH}$ faster than SO and EPB. BsuEH exhibited higher reaction rates in hydrolysis of EPB and $\mathrm{ECH}$. BsuEH hydrolyzed EPB faster than BpuEH. In hydrolysis of GT, BsuEH was slower than BpuEH.

\subsection{Optimal $p H$ and Temperature of Catalytic Reaction}

The effects of $\mathrm{pH}$ and temperature on hydrolytic activity were determined with GT as the substrate. As shown in Figure $3 \mathrm{~A}$ and $3 \mathrm{~B}, \mathrm{BsuEH}$ and $\mathrm{BpuEH}$ exhibited similar optimal $\mathrm{pH}$ and temperature for the hydrolytic reaction, with the highest catalytic activity at $\mathrm{pH} 7.2$ and $30^{\circ} \mathrm{C}$, respectively. However, at $\mathrm{pH}>7.8$ or temperature $>35$ ${ }^{\circ} \mathrm{C}$, the hydrolytic activity of $\mathrm{BsuEH}$ and $\mathrm{BpuEH}$ markedly decreased.

\subsection{Effects of Various Chemicals on Hydrolytic Reaction}

The effect of various chemicals (including metal ions and cosolvents) on enzyme activity was determined using racemic $\mathrm{SO}$ as the substrate. As shown in Figure 3C, the hydrolytic activity of both EHs was strongly inhibited by addition of $\mathrm{Ca}^{2+}$ and $\mathrm{Zn}^{2+}$ to the reaction mixture. $\mathrm{Mg}^{2+}$ and $\mathrm{Cu}^{2+}$ caused less inhibition of the EHs. $\mathrm{Mn}^{2+}$ and $\mathrm{Ba}^{2+}$ more strongly inhibited the catalytic activity of $\mathrm{BpuEH}$ than that of BsuEH. The hydrolytic activity of both BpuEH and BsuEH was tolerant to $10 \%$ acetonitrile and ethanol, but sensitive to EDTA- $\mathrm{Na}_{2}$ and SDS.

\subsection{Enantioselectivity of Hydrolytic Reaction}

To probe the catalytic stereoselectivity of the EHs toward various substrates, hydrolysis of $(R)$ and $(S)$ enantiomers of four epoxides was performed. Figure 4 indicates that the two EHs showed similar stereoselectivity. BpuEH and BsuEH exhibited higher enantioselectivity toward substrates with a larger side chain, like SO and GT, but almost no enantioselectivity toward ECH. These results suggest that both EHs have the potential to be used in kinetic resolution of some racemic epoxides for preparation of enantiopure diols and epoxides.
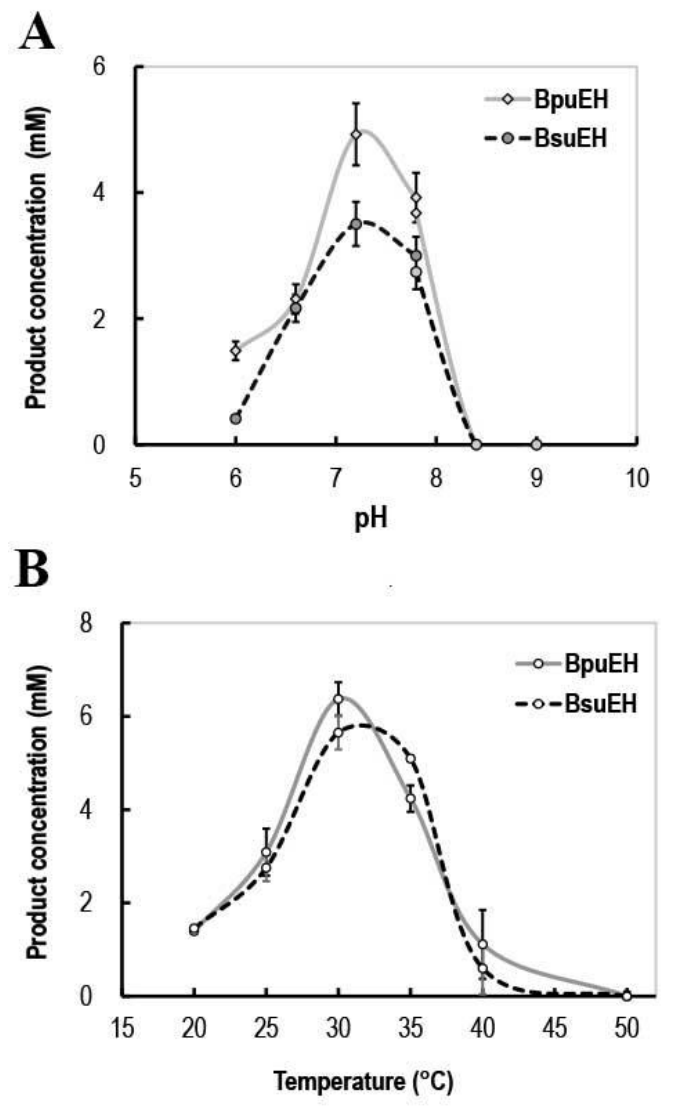

C

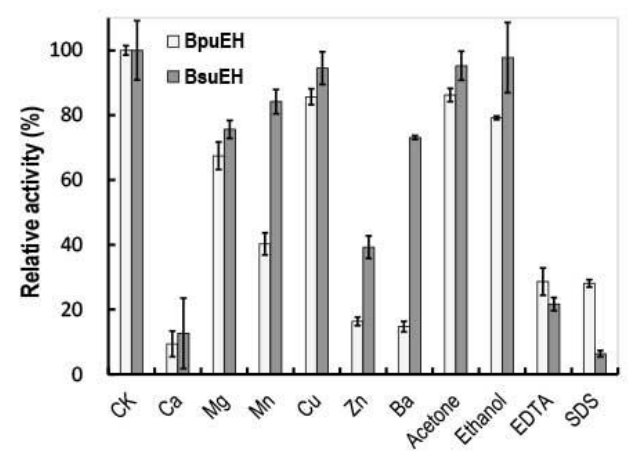

Figure 3. Effects of $\mathrm{pH}(\mathrm{A})$, temperature (B) and various chemicals (C) on the hydrolytic reactions of $\mathrm{BpuEH}$ and $\mathrm{BsuEH}$. The reaction was performed in $0.1 \mathrm{M}$ phosphate buffer ( $\mathrm{pH} 7.5$ ) using $2.5 \mu \mathrm{g}$ enzyme and $30 \mathrm{mM}$ substrate. In panel (C), CK indicates that no chemicals were added aside from the standard assay components, and the activity of the enzyme in these conditions was defined as $100 \%$. 


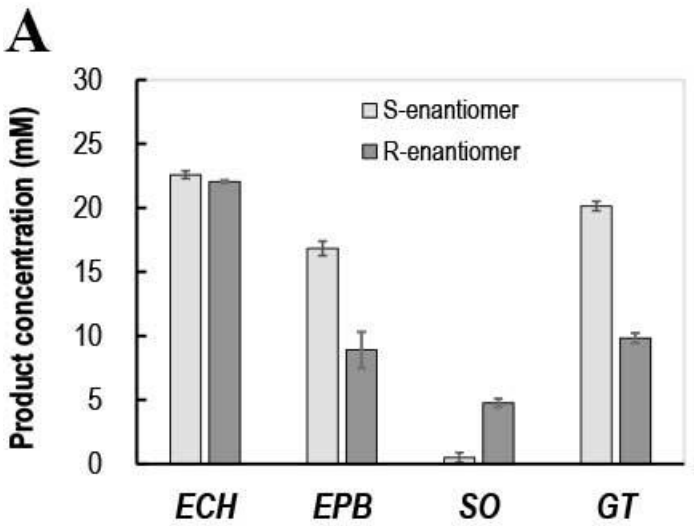

B

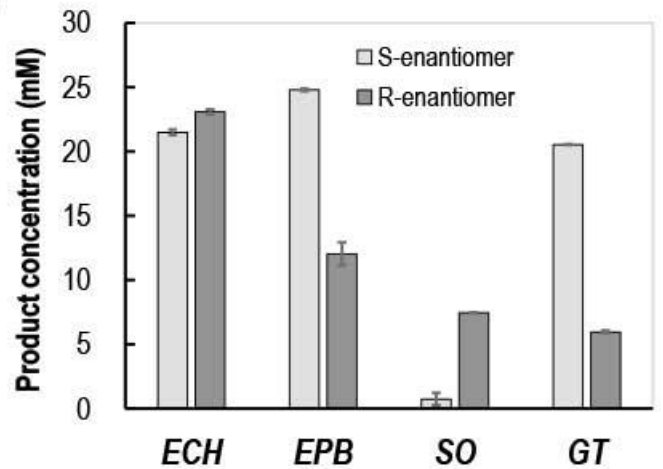

Figure 4. Stereoselective hydrolysis of $(R)-/(S)$-enantiomers of various epoxides by BpuEH (A) and BsuEH (B). EPB, 1,2epoxybutane; $\mathrm{ECH}$, epichlorohydrin; SO, styrene oxide; GT, glycidyl tosylate. The reaction was performed in $0.1 \mathrm{M}$ phosphate buffer ( $\mathrm{pH} 7.5)$ using $5 \mu \mathrm{g}$ enzyme and $30 \mathrm{mM}$ substrate at $35^{\circ} \mathrm{C}$ for $30 \mathrm{~min}$.

\section{Discussion}

In this work, genes from B. subtilis S1-4 and B. pumilus BA06 encoding EHs were successfully cloned and expressed in E. coli. Our results indicated that the induction temperature and the position of the His-tag had a significant impact on soluble expression of these two $\mathrm{EH}$; a His-tag fused to the C-terminus enhanced the soluble expression of these enzymes (Fig. 2). Similar results were reported in inducible expression of other heterologous genes in E. coli (30). An EH from marine bacterium Sphingophyxis alikeness was largely expressed in soluble form when a His-tag was fused to the Cterminus $(31,32)$. In contrast, soluble recombinant proteins with an $\mathrm{N}$-terminal fused His-tag could not be obtained in seven out of eight cases when expressing $\mathrm{EH}$-encoding cDNAs from the white-rot fungus Phanerochaete chrysosporium (33). Accordingly, various fusion tags have been adopted as a general strategy to produce recombinant proteins, which may not only enhance solubility of expressed proteins but also simplify the purification procedure (34). The His-tag is more popular fusion used in recombinant protein expression in E. coli. The position and even the sequence of His-tag could affect the solubility and expression efficiency of a given protein $(30,35)$. The reason may be ascribed to modulation of the protein 3-D structure by the His-tag. For example, by 3-D structural comparison of a bacterial laccase Lac15 with or without a His-tag fusion, the His-tag was recognized as the main reason for fold disturbation and formation of inclusion body (36). On the contrary, a 3-D structural homology modeling showed that a His-tag added at the N-terminus of $(+)-\gamma$ lactamase had no effect on the formation of inclusion bodies (37). Therefore, effect of the position of a Histag on solubility of the expressed proteins is different, perhaps depending on their 3-D structure. In the cases of EHs, a His-tag added at the N-terminus of microbial EHs may disturb the 3-D structure, favoring aggregation into inclusion bodies when recombinantly expressed in E. coli. Further, overexpression of EHs from microbes as maltose binding protein fusions is not always successful (23). However, coexpression of molecular chaperones was reported to enhance soluble expression of $\mathrm{EH}$ from Rhodotorula glutinis in E. coli (38). Therefore, enhancement of soluble expression of EHs is worth investigating in the future, so as to obtain sufficient $\mathrm{EH}$ to meet the requirements of biocatalysis.

$\mathrm{BpuEH}$ and $\mathrm{BsuEH}$ exhibited wide substrate specificity since they could hydrolyze four epoxides. The EH from B. subtilis 168 was reported to have narrower substrate specificity (23), but this may have been due to poor expression in E. coli. Further, BpuEH and BsuEH showed different stereoselectivity toward the enantiomers of some epoxides, i.e., selective hydrolysis of the epoxides with larger side chains such as SO and GT (Fig. 4). This phenomenon is often observed for EHs (10). For example, the EH from Novosphingobium aromaticivorans was reported to better hydrolyze the (R)-enantiomer of SO and ECH (22). In contrast, some EHs show low enantioselectivity toward different enantiomers (31).

The catalytic properties of BpuEH and BsuEH were also analyzed. They catalyzed the hydrolytic reaction in a narrow range of $\mathrm{pH}$ and temperature. Metal ions had various effects on the $\mathrm{EH}$ activity $(13,26)$. Hydrolytic activity of the both EHs was strongly inhibited by some divalent cations such as $\mathrm{Ca}^{2+}$ and $\mathrm{Zn}^{2+}$. On the other hand, $\mathrm{Mg}^{2+}, \mathrm{Mn}^{2+}$ and $\mathrm{Cu}^{2+}$ had less effect on the catalytic reaction (Fig. 3C). Similar results were reported for the other EHs. For example, the recombinant potato soluble $\mathrm{EH}$ was inhibited by $\mathrm{Zn}^{2+}$, $\mathrm{Ca}^{2+}$ and the other metal ions (39). Nevertheless, seldom explanations have been given for the loss in catalytic activity caused by the metal cations for the EHs. $\mathrm{Zn}^{2+}$ is known to interact with free thiol groups, which may cause inhibition as in case of 6-phosphogluconate dehydrogenase and yeast glutathione reductase (40, 41). In fact, there is only one cystine residue in the amino acid sequence of BpuEH and BsuEH (Fig. 1), which may be chosen for site-directed mutagenesis to test this hypothesis. In addition, in terms of the catalytic kinetics, inhibition of human soluble $\mathrm{EH}$ by $\mathrm{Zn}^{2+}$ was non-competitive, but noncompetitive for mouse soluble 
$\mathrm{EH}$, suggesting that the metal binding sites in the EHs may be different from the enzyme active center (39). It is known histidine residues in proteins can interacted with divalent metal ions. Several histidine residues including one of the active sites exist in all the EHs. Therefore, it is reasonable to conclude that these divalent cations like $\mathrm{Zn}^{2+}$ may also disturb the 3-D structure of the EHs through coordinating with these amino acid residues. Most recently, human histidine triad nucleotide binding protein 1 (hHintl) was reported to be inhibited by several divalent cations, and the crystal structure of hHint 1 revealed that $\mathrm{Cu}^{2+}$ could disrupt the second structure of the $\mathrm{C}$-terminus, leading to irreversible inactivation (42). However, $\mathrm{Ca}^{2+}$ does not inhibit many other EHs $(13,26,39)$. Therefore, the mechanism of inhibition by divalent cations appears to be species-specific and the metal binding site is different from the active site. In view of their sensitivity to metal ions, BpuEH and BsuEH are different from the EHs from other sources. However, both EHs reported here were tolerant to organic solvents, which is a prerequisite to perform catalytic reactions in biphasic systems (43).

\section{Conclusions}

In conclusion, homologous EHs from B. pumilus and B. subtilis were cloned and expressed in E. coli. Lower temperature and the position of a His-tag were vital in successful soluble expression. The recombinant EHs could catalyze hydrolysis of various epoxides and showed enantioselectivity in the ring-opening reaction of some epoxides, especially SO and GT with larger side chains. The two EHs were tolerant to organic solvents. However, protein engineering technologies like in vitro directed-evolution should be applied to the EHs to increase the stereoselective hydrolysis of racemic epoxides and improve soluble expression of the enzymes. Taken together, the EHs from two Bacillus species show potential for application in kinetic resolution of racemic epoxides to prepare enantiopure epoxides and vicinal diols.

\section{Conflict of Interest}

There is no conflict of interest with this study.

\section{Acknowledgements}

This work was supported by the National Science Foundation of China (Project no. 31171204). We thank James Allen, DPhil, from Liwen Bianji, Edanz Group China (www.liwenbianji.cn/ac), for editing the English text of a draft of this manuscript.

\section{References}

1. Jacobsen EN. Asymmetric catalysis of epoxide ringopening reactions. Acc Chem Res. 2000;33(6):421-431. pmid: 10891060

2. Tokunaga M, Larrow JF, Kakiuchi F, Jacobsen EN. Asymmetric catalysis with water: efficient kinetic resolution of terminal epoxides by means of catalytic hydrolysis. Science. 1997;277(5328):936-938. pmid: 9252321

3. Archelas A, Furstoss R. Synthetic applications of epoxide hydrolases. Curr Opin Chem Biol. 2001;5(2):112-119. doi: 10.1016/s13675931(00)00179-4 pmid: 11282336

4. Saini P, Sareen D. An Overview on the Enhancement of Enantioselectivity and Stability of Microbial Epoxide Hydrolases. Mol Biotechnol. 2017;59(2-3):98-116. doi: 10.1007/s12033-017-9996-8 pmid: 28271340

5. Lin $\mathrm{H}$, Liu J-Y, Wang H-B, Ahmed AAQ Wu Z-L. Biocatalysis as an alternative for the production of chiral epoxides: A comparative review. Journal of Molecular Catalysis B: Enzymatic. 2011;72(3-4):77-89. doi: 10.1016/j.molcatb.2011.07.012

6. Barth S, Fischer M, Schmid RD, Pleiss J. Sequence and structure of epoxide hydrolases: a systematic analysis. Proteins. 2004;55(4):846-855. doi: 10.1002 /prot.20013 pmid: 15146483

7. Fretland AJ, Omiecinski CJ. Epoxide hydrolases: biochemistry and molecular biology. Chem Biol Interact. 2000;129(1-2):41-59. doi: 10.1016/s00092797(00)00197-6 pmid: 11154734

8. Sareen D, Kumar R. Prospecting for efficient enantioselective epoxide hydrolases. Indian J Biotechnol. 2011;10(10):161-177.

9. Widersten M, Gurell A, Lindberg D. Structure-function relationships of epoxide hydrolases and their potential use in biocatalysis. Biochim Biophys Acta. 2010;1800(3):316-326. doi: 10.1016/j.bbagen.2009.11.014 pmid: 19948209

10. Orru RV, Faber K. Stereoselectivities of microbial epoxide hydrolases. Curr Opin Chem Biol. 1999;3(1):16-21. doi: 10.1016/s13675931(99)80004-0 pmid: 10021403

11. Archelas A, Iacazio G, Kotik M. Epoxide Hydrolases and their Application in Organic Synthesis. 2016:179-229. doi: $10.1002 / 9781118828083 . c h 8$

12. Woo JH, Kang JH, Hwang YO, Cho JC, Kim SJ, Kang SG. Biocatalytic resolution of glycidyl phenyl ether using a novel epoxide hydrolase from a marine bacterium, Maritimibacter alkaliphilus KCCM 42376 [corrected]. J Biosci Bioeng. 2010;109(6):539-544. doi: 10.1016/j.jbiosc.2009.11.019 pmid: 20471590

13. Xue F, Liu Z-Q, Zou S-P, Wan N-W, Zhu W-Y, Zhu Q, et al. A novel enantioselective epoxide hydrolase from Agromyces mediolanus ZJB120203: Cloning, characterization and application. Process Biochemistry. 2014;49(3):409-417.

10.1016/j.procbio.2014.01.003

14. Wu K, Wang H, Sun H, Wei D. Efficient kinetic resolution of phenyl glycidyl ether by a novel epoxide hydrolase from Tsukamurella paurometabola. Appl Microbiol Biotechnol. 2015;99(22):9511-9521. doi: 10.1007/s00253-015-6716-9 pmid: 26088175

15. Archelas A, Zhao W, Faure B, Iacazio G, Kotik M. Epoxide hydrolase-catalyzed enantioselective conversion of trans-stilbene oxide: Insights into the reaction mechanism from steady-state and pre-steadystate enzyme kinetics. Arch Biochem Biophys. 2016;591:66-75. doi: 10.1016/j.abb.2015.12.008 pmid: 26714303 
16. Wilson C, De Oliveira GS, Adriani PP, Chambergo FS, Dias MVB. Structure of a soluble epoxide hydrolase identified in Trichoderma reesei. Biochim Biophys Acta Proteins Proteom. 2017;1865(8):1039-1045. doi: 10.1016/j.bbapap.2017.05.004 pmid: 28502798

17. Kotik M, Archelas A, Famerova V, Oubrechtova P, Kren V. Laboratory evolution of an epoxide hydrolase towards an enantioconvergent biocatalyst. J Biotechnol. 2011;156(1):1-10. doi: 10.1016/j.jbiotec.2011.08.003 pmid: 21854816

18. Kong XD, Yuan S, Li L, Chen S, Xu JH, Zhou J. Engineering of an epoxide hydrolase for efficient bioresolution of bulky pharmaco substrates. Proc Natl Acad Sci U S A. 2014;111(44):15717-15722. doi: 10.1073/pnas. 1404915111 pmid: 25331869

19. Zou SP, Zheng YG, Wu Q, Wang ZC, Xue YP, Liu ZQ. Enhanced catalytic efficiency and enantioselectivity of epoxide hydrolase from Agrobacterium radiobacter $\mathrm{AD} 1$ by iterative saturation mutagenesis for (R)epichlorohydrin synthesis. Appl Microbiol Biotechnol. 2018;102(2):733-742. doi: 10.1007/s00253-0178634-5 pmid: 29151159

20. Zhu QQ, He WH, Kong XD, Fan LQ, Zhao J, Li SX, et al. Heterologous overexpression of Vigna radiata epoxide hydrolase in Escherichia coli and its catalytic performance in enantioconvergent hydrolysis of $\mathrm{p}$ nitrostyrene oxide into (R)-p-nitrophenyl glycol. Appl Microbiol Biotechnol. 2014;98(1):207-218. doi: 10.1007/s00253-013-4845-6 pmid: 23615737

21. Hu D, Tang CD, Yang B, Liu JC, Yu T, Deng C, et al. Expression of a novel epoxide hydrolase of Aspergillus usamii E001 in Escherichia coli and its performance in resolution of racemic styrene oxide. J Ind Microbiol Biotechnol. 2015;42(5):671-680. doi: 10.1007/s10295015-1604-y pmid: 25733186

22. Woo JH, Hwang YO, Kang JH, Lee HS, Kim SJ, Kang SG. Enantioselective hydrolysis of racemic epichlorohydrin using an epoxide hydrolase from Novosphingobium aromaticivorans. J Biosci Bioeng. 2010;110(3):295-297.

doi: 10.1016/j.jbiosc.2010.02.014 pmid: 20547378

23. van Loo B, Kingma J, Arand M, Wubbolts MG, Janssen DB. Diversity and biocatalytic potential of epoxide hydrolases identified by genome analysis. Appl Environ Microbiol. 2006;72(4):2905-2917. doi: 10.1128/AEM.72.4.2905-2917.2006 pmid: 16597997

24. Yong B, Yang BQ, Zhao CW, Feng H. Draft Genome Sequence of Bacillus subtilis Strain S1-4, Which Degrades Feathers Efficiently. Genome Announc. 2013;1(5). doi: 10.1128/genomeA.00766-13 pmid: 24072866

25. Zhao CW, Wang HY, Zhang YZ, Feng H. Draft genome sequence of Bacillus pumilus BA06, a producer of alkaline serine protease with leather-dehairing function. J Bacteriol. 2012;194(23):6668-6669. doi: 10.1128/JB.01694-12 pmid: 23144411

26. Li N, Zhang Y, Feng H. Biochemical characterization and transcriptional analysis of the epoxide hydrolase from white-rot fungus Phanerochaete chrysosporium. Acta Biochim Biophys Sin (Shanghai). 2009;41(8):638647. doi: 10.1093/abbs/gmp052 pmid: 19657565

27. Wu S, Shen J, Zhou X, Chen J. A novel enantioselective epoxide hydrolase for (R)-phenyl glycidyl ether to generate (R)-3-phenoxy-1,2-propanediol. Appl
Microbiol Biotechnol. 2007;76(6):1281-1287. doi: 10.1007/s00253-007-1098-2 pmid: 17710393

28. Shimizu K-i, Sakamoto M, Hamada M, Higashi T, Sugai $\mathrm{T}$, Shoji $\mathrm{M}$. The scope and limitation of the regio- and enantioselective hydrolysis of aliphatic epoxides using Bacillus subtilis epoxide hydrolase, and exploration toward chirally differentiated tris(hydroxymethyl)methanol. Tetrahedron: Asymmetry. 2010;21(16):2043-2049. doi: 10.1016/j.tetasy.2010.07.014

29. Bala N, Chimni SS, Saini HS, Chadha BS. Bacillus alcalophilus MTCC10234 catalyzed enantioselective kinetic resolution of aryl glycidyl ethers. Journal of Molecular Catalysis B: Enzymatic. 2010;63(3-4):128134. doi: 10.1016/j.molcatb.2009.12.019

30. Li L, Xie T, Liu Z, Feng H, Wang G. Activity enhancement of CotA laccase by hydrophilic engineering, histidine tag optimization and static culture. Protein Eng Des Sel. 2018;31(1):1-5. doi: 10.1093/protein/gzx064 pmid: 29301022

31. Kang JH, Woo JH, Kang SG, Hwang YO, Kim SJ. A cold-adapted epoxide hydrolase from a strict marine bacterium, Sphingophyxis alaskensis. J Microbiol Biotechnol. 2008;18(8):1445-1452. pmid: 18756107

32. Negahdary M, Omidi S, Eghbali-Zarch A, Mousavi SA, Mohseni G. Plant synthesis of silver nanoparticles using Matricaria chamomilla plant and evaluation of its antibacterial and antifungal effects. Biomed Res. 2015;26:794-799.

33. Li N. Cloning, expression and characterization of epoxide hydrolases from Phanerochaete chrysosporium. China: Sichuan University; 2009.

34. Esposito D, Chatterjee DK. Enhancement of soluble protein expression through the use of fusion tags. Curr Opin Biotechnol. 2006;17(4):353-358. doi: 10.1016/j.copbio.2006.06.003 pmid: 16781139

35. Osadska M, Bonkova H, Krahulec J, Stuchlik S, Turna J. Optimization of expression of untagged and histidinetagged human recombinant thrombin precursors in Escherichia coli. Appl Microbiol Biotechnol. 2014;98(22):9259-9270. doi: 10.1007/s00253-0145840-2 pmid: 24878753

36. Fang Z, Zhou P, Chang F, Yin Q, Fang W, Yuan J, et al. Structure-based rational design to enhance the solubility and thermostability of a bacterial laccase Lac15. PLoS One. 2014;9(7):e102423. doi: 10.1371/journal.pone. 0102423 pmid: 25036001

37. Zhu S, Gong C, Ren L, Li X, Song D, Zheng G. A simple and effective strategy for solving the problem of inclusion bodies in recombinant protein technology: His-tag deletions enhance soluble expression. Appl Microbiol Biotechnol. 2013;97(2):837-845. doi: 10.1007/s00253-012-4630-y pmid: 23250226

38. Visser H, De Oliveira Villela Filho M, Liese A, Weijers CAGM, Verdoes JC. Construction and Characterisation of a Genetically Engineered Escherichia coli Strain for the Epoxide Hydrolasecatalysed Kinetic Resolution of Epoxides. Biocatalysis and Biotransformation. 2009;21(1):33-40. doi: 10.1080/1024242031000076215

39. Draper AJ, Hammock BD. Inhibition of soluble and microsomal epoxide hydrolase by zinc and other metals. Toxicol Sci. 1999;52(1):26-32. doi: 10.1093/toxsci/52.1.26 pmid: 10568695 
40. Niehaus WG, Richardson SB, Wolz RL. Slow-binding inhibition of 6-phosphogluconate dehydrogenase by zinc ion. Arch Biochem Biophys. 1996;333(2):333-337. doi: 10.1006/abbi.1996.0399 pmid: 8809071

41. Tandogan B, Ulusu NN. The inhibition kinetics of yeast glutathione reductase by some metal ions. J Enzyme Inhib Med Chem. 2007;22(4):489-495. doi: 10.1080/14756360601162147 pmid: 17847717

42. Shah R, Chou TF, Maize KM, Strom A, Finzel BC, Wagner CR. Inhibition by divalent metal ions of human histidine triad nucleotide binding protein 1 (hHint1), a regulator of opioid analgesia and neuropathic pain. Biochem Biophys Res Commun. 2017;491(3):760-766. doi: 10.1016/j.bbrc.2017.07.111 pmid: 28739258

43. Hu D, Wang R, Shi XL, Ye HH, Wu Q, Wu MC, et al. Kinetic resolution of racemic styrene oxide at a high concentration by recombinant Aspergillus usamii epoxide hydrolase in an $n$-hexanol/buffer biphasic system. J Biotechnol. 2016;236:152-158. doi: 10.1016/j.jbiotec.2016.08.013 pmid: 27546798 